\title{
Perceptions of teacher candidates concerning ethically suitable behaviours for teaching profession
}

\author{
Süleyman Balc1 ${ }^{1 \mathrm{a}}$ \\ ${ }^{1}$ Kırıkkale University, Education Faculty, Guidance and Counseling Department, Yahşihan, \\ Kırıkkale, 71450 Turkey
}

\begin{abstract}
Identifying the perceptions of teacher candidates regarding effective teacher charactheristics and teaching is necessary for knowing their program experiences to consider the appropriateness of those perceptions in terms of professional purposes and practices. Moreover, professional ethics determined for teaching profession enable teachers to make decisions easily at any difficult situations in education. Purpose of this study is to describe perceptions of teacher candidates working for secondary schools concerning ethically suitable behaviors for teaching profession. Participants of this study includes graduates of Mathematics, Nursing, Sociology, Turkish Language Literature Departments. Of those participants ( $\mathrm{n}=163), 42$ are graduates of Mathematics, 35 are Nursing, 45 are Sociology, 41 are Turkish Language Literature Departments and completed preservice teacher education curriculum (pedagogical education program) at Education Faculty of Kırıkkale University in 2014-2015 academic calender. According to the results of this study most of the participants are aware of ethically suitable behaviors for teaching profession.
\end{abstract}

Keywords: Teacher Candidates; Perceptions of Teacher Candidates; Ethically Suitable Behaviors

\section{Problem and significance of the study}

Identifying the perceptions of teacher candidates regarding effective teachers and teaching is required for knowing their program experiences that are necessary to consider the appropriateness of those perceptions in terms of professional purposes and practices [6]. Moreover, in order to make necessary changes regarding teaching practices and teacher education programs teachers' beliefs and perceptions are required to be taken into consideration [5]. Ethical behaviours of teachers provide positive contribution to students' moral development and schools become one of places where ethical behaviour is taught. Professional ethics of teaching profession determine professional attitudes and responsibilities regarding services given by teachers [8]. For example, ethical principles determined for teachers enable teachers make decisions easily at any situations in profession of teaching. The ethical aspect of the teachers' teaching practices influence the

${ }^{\text {a }}$ Corresponding author: meb.suleyman@gmail.com 
ethical climate in schools directly or indirectly [2]. Moreover, ethically suitable decisions and behaviours of teachers during teaching practices are able to improve their education so that they can make an effective contribution to the development of student [4]. With these features teachers are able to influence students mentally, emotionally, spiritually and physically. By this way, teachers try to enable students to develop their capacities and to behave responsibly and ethically by making their works in the most appropriate manner. Consequently, profession of teaching constitutes basics of schools and basics of a community which are sensitive to ethical principles.

Some of the teacher associations have determined ethical principles for teachers such as Association of American Educators (AAE) and another teacher association from Canada. AAE have developed code of ethics for educators. This code of ethics includes four basic principles concerning the rights of students and educators. These principles are determined by AAE and stated briefly as following [1]:

1. Ethical conduct toward students: This principle states that the professional educator accepts personal responsibility for teaching students character qualities that will help them evaluate the consequences of and accept the responsibility for their actions and choices. Therefore, all educators are obligated to help foster civic virtues such as integrity, diligence, responsibility, cooperation, loyalty, fidelity, and respect for the law, for human life, for others, and for self.

2. Ethical conduct toward practices and performance: This principle states that the professional educator is expected to show responsibility and accountability for his or her performance and continually strives to demonstrate competence and to maintain the dignity of the profession by respecting and obeying the law and by demonstrating personal integrity.

3. Ethical conduct toward professional colleagues: This principle states that the professional educator is expected to accord just and equitable treatment to all members of the profession in exemplifying ethical relations with colleagues.

4. Ethical conduct toward parents and community: This principle states that the professional educator is expected to recognize that quality education is the common goal of the public, boards of education, and educators, and that a cooperative effort is essential among these groups to attain that goal.

Members of the Ontario College of Teachers as another teacher association from Canada have determined ethical standards for teaching profession in order to inspire teachers to reflect and uphold the honour and dignity of the teaching profession, to identify the ethical responsibilities and commitments in the teaching profession, to guide ethical decisions and actions in the teaching profession, and to promote public trust and confidence in the teaching profession [7]. These ethical standards are stated as following:

1. Care: This includes compassion, acceptance, interest and insight for developing students' potential and means that teachers express their commitment to students' wellbeing and learning through positive influence, professional judgment and empathy in practice.

2. Respect: This means that teachers honour human dignity, emotional wellness and cognitive development and model respect for spiritual and cultural values, social justice, confidentiality, freedom, democracy and the environment.

3. Trust: This includes that teachers' professional relationships with students, colleagues, parents, guardians and the public are based on fairness, openness, honesty and trust.

4. Integrity: This states that teachers follow honesty, reliability and moral action in their professional commitments and responsibilities.

Some ethical concepts related with ethically suitable behaviours of teachers were determined by the researcher by using aforementioned ethical principles developed by two 
different teacher association. These concepts are care, trust, respect, integrity and behaviour modelling. Therefore, the aim of this study is to describe perceptions of teacher candidates of secondary schools regarding ethically suitable behaviours of teachers during practice of teaching in terms of these concepts.

\section{Method}

\subsection{Research Model}

In this study perceptions of teacher candidates of secondary schools regarding ethically suitable behaviours of teachers during practice of teaching were analysed by using qualitative research technique.

\subsection{Sample}

In this study Purposeful sampling technique were used to determine the participants. Participants of this study is teacher candidates of secondary schools $(n=163)$ who are university graduates and completed preservice teacher education curriculum courses (pedagogical education program) at Education faculty of Kırıkkale University in 20142015 academic year. Of those university graduates, 42 are graduated from Mathematics; 35 are graduated from Nursing ; 45 are graduated from Sociology and 41 are graduated from Turkish Language Literature.

\subsection{Data collection}

An open ended question were asked to participants and demanded to write down their perceptions as answer for this question "According to you what are the features of a teacher who behaves ethically and who has ethical principles?" and their responses were taken in written form.

\subsection{Data analysis}

After analysing participant's written responses, content of written responses were clustered into a frame of related themes. By this way, written responses of participants were organized logically. Then, themes related with the content were determined. Words, expressions and sentences were coded for stating these themes clearly and categories were determined for each theme. Finally, percentages of each theme were calculated to produce meaningful description about perceptions of participants.

\section{Findings}

Perceptions of participants were organized in terms of 5 themes. These themes are care, trust, respect, integrity and behavior modeling. Categories determined for each theme are as following: Care includes knowing student and student's family, showing effort to reach student, trying to understand student's problems, having good communication, being patient, being nurturing, listening to student carefully. Trust includes being fair and showing equality in classroom, being fair during determining scores and grades of lessons and courses, establishing relationship with all students equally. Respect includes using expressions with respectful manner to students, using objective conversation manner, being 
respectful to thoughts and beliefs of students, being respectful to social values of community. Integrity includes being fair, being truthful and reliable and being democratical. Behavior modeling includes being tolerant, renewing himself/herself, being moral and educative, being sincerely, managing class effectively, teaching well. Sample perceptions of participants were given as example for each category in Table 1.

Table 1. Examples of perceptions concerning themes and categories

\begin{tabular}{lll}
\hline Themes & Categories & Examples of perceptions \\
\hline Care & knowing student and & Teachers should know student's social environment, \\
& student's family, showing & family relations, economical stuations, have \\
& effort to reach student, & communication with family of student one-by-one, \\
& trying to understand & should understand student, be able to help \\
& student's problems, having & development and adjustment of student. \\
& good communication, being & Teachers should search the reasons if student don't \\
patient, being nurturing, & want to come school, able to help student to solve \\
listening to student & his/her problems, should be aware of differences \\
& carefully. &
\end{tabular}

Respect using expressions with

Teachers should listen to students carefully while respectful manner to they are speaking, and give them equal opportunity students, using objective to speak.

conversation manner, being respectful to thoughts and beliefs of students, being respectful to social values of community.

Trust being fair and showing equality in classroom, being fair during determining scores and grades of lessons and courses, establishing relationship with all students equally

Integrity being fair, being truthful and reliable and being democratical

Teachers do not discriminate, act honestly, maintain the distance between students, do not evaluate students according to their physical appereance, provide support to be respectful individuals to other's desicions.

Teachers show fair attitudes to all students, answer students' questions objectively, have equal distance towards all students and do not clarify their political thought or ideas during lesson.

Behavior being tolerant, modeling renewing himself/herself, being moral and educative, being sincerely, managing class effectively, teaching well.

Teachers act flexibly against problems, renew his/her knowledge about students constantly, live according to what he/she says, raise students with democraticminded, follow the technological developments and use them in education.

Teachers should become an role model with his/her morality, behavior, conversation, have work ethics, maintain control within class and be aware of his/her responsibilities. 
Perceptions of teacher candidates of secondary schools were analysed according to the themes and the categories concerning these themes were determined. Percentages of each theme were calculated to produce meaningful description about perceptions of participants and given in Table 2 .

Table 2. Percentages of perceptions in terms of themes and departments

\begin{tabular}{lcccc}
\hline Themes & Mathematics & Nursing & Sociology & Literature \\
\hline Care & 41 & 59 & 55 & 32 \\
Trust & 62 & 55 & 49 & 30 \\
Respect & 61 & 44 & 21 & 57 \\
Integrity & 40 & 24 & 29 & 51 \\
Behavior modelling & 25 & 45 & 58 & 35 \\
\hline
\end{tabular}

As seen in Table 2 participant's perceptions were clustered into five themes concerning ethically suitable behaviors of teachers. In terms of graduated departments in the theme of care, $41 \%$ of Mathematics graduates, $59 \%$ of Nursing graduates, $55 \%$ of Sociology graduates and $32 \%$ of Literature graduates stated that teacher with ethically suitable behaviour should have caring behaviour such as knowing student and student's family, showing effort to reach student, trying to understand student's problems, having good communication, being patient, being nurturing and listening to student carefully.

Concerning the theme of trust, $62 \%$ of Mathematics graduates, $55 \%$ of Nursing graduates, $49 \%$ of Sociology graduates and $30 \%$ of Literature graduates felt that trustful behaviour such as being fair and showing equality in classroom, being fair during determining scores and grades of lessons and courses, establishing relationship with all students equally is necessary for teacher with ethically suitable behaviour.

Concerning the theme of respect, $61 \%$ of Mathematics graduates, $44 \%$ of Nursing graduates, $21 \%$ of Sociology graduates and $57 \%$ of Literature graduates saw respectful behaviour such as using expressions with respectful manner to students, using objective conversation manner, being respectful to thoughts and beliefs of students, being respectful to social values of community is essential for teacher with ethically suitable behaviour.

Concerning the theme of integrity, $40 \%$ of Mathematics graduates, $24 \%$ of Nursing graduates, $29 \%$ of Sociology graduates and $51 \%$ of Literature graduates saw integrity such as being fair, being truthful and reliable and being democratical is essential for teacher with ethically suitable behaviour.

Concerning the behavior modelling, $25 \%$ of Mathematics graduates, $45 \%$ of Nursing graduates, $58 \%$ of Sociology graduates and $35 \%$ of Literature graduates saw behavior modelling such as being tolerant, renewing himself/herself, being moral and educative, being sincerely, managing class effectively, teaching well is essential for teacher with ethically suitable behaviour.

Findings of this study show that there are differences among perceptions of teacher candidates in terms of themes. In the theme of care most of the related perceptions were stated by Nursing graduates with $59 \%$ and least of the related perceptions were expressed by Literature graduates with $32 \%$. In the theme of trust most of the related perceptions were by stated Mathematics graduates with $62 \%$ and least of the related perceptions were expressed by Literature graduates with $30 \%$. Concerning the theme of respect, most of the related perceptions were stated by Mathematics graduates with $61 \%$ and least of the related perceptions were expressed by Sociology graduates with $21 \%$. Concerning the theme of integrity, most of the related perceptions were stated by Literature graduates with $51 \%$ and least of the related perceptions were expressed by Nursing graduates with $24 \%$. In the theme of behavior modelling most of the related perceptions were stated by Sociology graduates with $58 \%$ and least of the related perceptions were expressed by Mathematics 
graduates with $25 \%$. Results of this study indicate that most of the participants are aware of ethical principles during teaching profession.

\section{Conclusion}

By considering their influence on the lives of students in a school, it can be said that teachers are required to serve as positive role models and demonstrate ethical behaviors while they interact with students, colleagues, parents and others in order to provide a safe and positive learning experience and it is necessary for teachers to maintain ethical behavior in professional practice by accurately representing and maintaining necessary qualifications for all of their responsibilities. Moreover, teachers are expected to provide a quality education to all students by interacting with them appropriately and by maintaining professional contact with their parents without discriminating against any students and without taking advantage of students in any way.

\section{References}

1. AAE (Association of American Educators) Code of Ethics for Educators. [Online] Available http://www.aaeteachers.org/index.php/about-us/aae-code-of-ethics (May, 2016)

2. Campbell, E.Moral lessons: The ethical role of teachers. Educational Research and Evaluation, 9, 25-50 (2003)

3. Carr, D. Moral educational implications of rival conceptions of education and the role of the teacher, Journal of Moral Education, 32:3, 219-232 (2003)

4. Coldron, J. and Smith R. Active location in teachers' construction of their professional identities, Journal of Curriculum Studies, 31:6, 711-726 (1999)

5. Hart, L. Preservice teachers' beliefs and practice after participating in an integrated content/methods courses. School Science \& Mathemutics, 102: 4-14 (2002)

6. Minor, L. C., A. J. Onwuegbuzie , A. E. Witcher \& T.L. James Preservice teachers' educational beliefs and their perceptions of characteristics of effective teachers, The Journal of Educational Research, 96:2, 116-127, DOI:10.1080/00220670209598798 (2002)

7. Members of the Ontario College of Teachers (MOCT) The Ethical Standards for the Teaching Profession. [Online] Available http://www.oct.ca/public/professionalstandards/ethical-standards (May, 2016)

8. Simpson, C. Should I or shouldn't I? An Ethical Conundrum. Library Media Connection, 23:2, 18-21 (2004) 